\title{
Commentary: To use or not to use? This is the question
}

\author{
Yaron D. Barac, MD, PhD
}

\author{
From the Division of Cardiovascular and Thoracic Surgery, Rabin Medical Center, Petach Tikva, Israel; and The \\ Sackler Faculty of Medicine, Tel Aviv University, Tel Aviv, Israel. \\ Disclosures: Author has nothing to disclose with regard to commercial support. \\ Received for publication July 6, 2019; accepted for publication July 8, 2019; available ahead of print Aug 6, 2019. \\ Address for reprints: Yaron D. Barac, MD, PhD, The Division of Cardiovascular and Thoracic Surgery, Rabin \\ Medical Center, Petach-Tikva, Israel, Sackler Faculty of Medicine, Tel Aviv University, Tel Aviv, Israel \\ (E-mail: yaronbar@icloud.com). \\ J Thorac Cardiovasc Surg 2020;159:1343-4 \\ $0022-5223 / \$ 36.00$ \\ Copyright (c) 2019 by The American Association for Thoracic Surgery \\ https://doi.org/10.1016/j.jtcvs.2019.07.003
}

In this issue of the Journal, Oras and colleagues ${ }^{1}$ address one of the most fundamental questions of organ allocation from a regional transplant center perspective: the use of hearts with a newly diagnosed left ventricular (LV) dysfunction. In their study, the records of organ donors in western Sweden between 2006 and 2016 were reviewed, and the outcomes of the recipients were evaluated. Of 641 potential heart donors, LV dysfunction, defined as an ejection fraction (EF) less than $50 \%$ or regional hypokinesia, was found in $155(24 \%)$. A total of $338(54 \%)$ donor hearts were eventually transplanted, and 45 (14\%) of these had LV dysfunction. Posttransplant echocardiography confirmed LV function normalization in these patients; moreover, no difference was found in either short-term outcomes or the composite end point of death or retransplantation with time between recipients of donor hearts with versus without LV dysfunction. Oras and colleagues ${ }^{1}$ conclude that cardiac dysfunction after brain death is common but often transient, and such hearts therefore can safely be transplanted and thus increase the donor pool.

Oras and colleagues ${ }^{1}$ confirmed the results of Sibona and colleagues, ${ }^{2}$ which addressed this dilemma with the United Network for Organ Sharing database between January 2000 and March 2016. Among 31,712 donor hearts that were transplanted, no significant differences were found in recipient survival out to 15 years of follow-up between patients with and without LV dysfunction. ${ }^{2}$ Furthermore, when using Cox regression analysis after adjustment for propensity variation in EF, Sibona and colleagues ${ }^{2}$ found it to have no statistically significant impact on mortality when analyzed as a categoric or continuous variable and also found that LV EF normalized 1 year posttransplant.

A unique strength of Oras and colleague's study ${ }^{1}$ lies within the description of the association between the use of inotropic support and cardiac arrest to LV dysfunction, as well as the fact that patients who had cardiac arrest had a better chance to have LV dysfunction recovery. These facts should be considered in the future when contemplating the use of donor hearts with LV dysfunction.

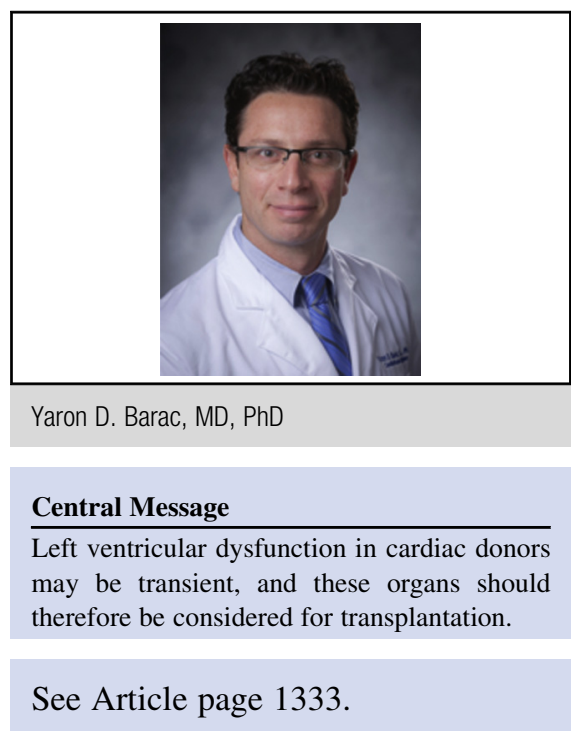

One should keep in mind several of the study limitations. Although guidelines suggest not using donor hearts with EF lower than $40 \%$, the cutoff for $\mathrm{LV}$ dysfunction of Oras and colleagues ${ }^{1}$ was an EF lower than $50 \%$, a fact that may have contributed to the high percentage of cardiac recovery. Furthermore, no protocolized echocardiography in predefined intervals after the identification of LV dysfunction were performed, and the time of procurement from the time of declared brain death was neither reported nor uniform. The hearts thus may still have been under the hormonal storm, and they were procured before being given a chance to recover (too close to the brain death), as previously suggested in lung transplantation. . $^{3,4}$

Finally, Oras and colleagues ${ }^{1}$ are to be commended for a well-executed study in an era when organ care systems (eg, that of TransMedics) are being used to mitigate the related risks associated with the use of marginal organs and those donated after cardiac death (eg, LV dysfunction). Future studies should try to characterize the group of marginal organs that will benefit the most from the use of organ care systems and those organs that do not need it, because the use of organ care systems comes with a price (eg, organ edema) that may have future effects that are still not fully understood. ${ }^{5,6}$

\section{References}

1. Oras J, Doueh R, Norberg E, Redfors B, Omerovic E, Dellgren G. Left ventricular dysfunction in potential heart donors and its influence on recipient outcomes. J Thorac Cardiovasc Surg. 2020;159:1333-41.e6. 
2. Sibona A, Khush KK, Oyoyo UE, Martens TP, Hasaniya NW, Razzouk AJ, et al. Long-term transplant outcomes of donor hearts with left ventricular dysfunction. J Thorac Cardiovasc Surg. 2019;157:1865-75.

3. Khush KK. Donor selection in the modern era. Ann Cardiothorac Surg. 2018;7: 126-34.

4. Wauters S, Verleden GM, Belmans A, Coosemans W, De Leyn P, Nafteux P, et al Donor cause of brain death and related time intervals: does it affect outcome after lung transplantation? Eur J Cardiothorac Surg. 2011;39:e68-76.
5. Ardehali A, Esmailian F, Deng M, Soltesz E, Hsich E, Naka Y, et al. PROCEED II Trial Investigators. Ex-vivo perfusion of donor hearts for human heart transplantation (PROCEED II): a prospective, open-label, multicentre, randomised noninferiority trial. Lancet. 2015;385:2577-84.

6. Mehta V, Taylor M, Hasan J, Dimarakis I, Barnard J, Callan P, et al. Establishing a heart transplant programme using donation after circulatory-determined death donors: a United Kingdom based single-centre experience. Interact Cardiovasc Thorac Surg. 2019;29:422-9. 